\title{
Trajetórias de mulheres camponesas no Espírito Santo: permanências e descontinuidades
}

\author{
Deiviani de Oliveira ${ }^{1}$, Luan Eudair Bridi ${ }^{2}$, Miriã Lúcia Luiz ${ }^{3}$, Regina Godinho de Alcântara ${ }^{4}$ \\ 1, 2, 3, ${ }^{4}$ Universidade Federal do Espírito Santo - UFES. Departamento de Educação, Política e Sociedade / Departamento de \\ Linguagens, Cultura e Educação. Avenida Fernando Ferrari, 514, Goiabeiras. Vitória - ES. Brasil. \\ Autor para correspondência/Author for correspondence: deivianioliveira@gmail.com
}

\begin{abstract}
RESUMO. Este texto visa compreender a trajetória de mulheres camponesas no Espírito Santo no período de 1930 a 2017, na busca pela compreensão dos modos como viveram/vivem e perceberam/percebem sua infância, trajetórias pessoais, processos de inserção como trabalhadoras e partícipes dos espaços sociais de suas comunidades, bem como os sentidos que a escolarização assume ao longo de suas vidas. Privilegia como aporte teórico-metodológico o pensamento de Carlo Ginzburg $(1988,1989,2002,2007)$, com os pressupostos da microhistória e do paradigma indiciário, e o de Mikhail Bakhtin (2003, 2004), tomando as narrativas como enunciados concretos. Como fonte, analisa os discursos/narrativas de quatro mulheres camponesas capixabas materializadas nos Cadernos da Realidade dos estudantes da Licenciatura em Educação do Campo/UFES. As análises indiciam permanências e descontinuidades nas trajetórias das mulheres capixabas no período investigado. Como permanências, destaca-se a mulher ocupando os espaços domésticos, sobretudo, exercendo atividades hercúleas, desprovidas de valor econômico. Ademais, o modelo patriarcal de família/sociedade presentifica-se nas narrativas e nos registros de mulheres de diferentes tempos geracionais. Emana dos documentos indícios de descontinuidades, tais como: a inserção ainda criança no processo de escolarização, o protagonismo das mulheres no âmbito doméstico, comunitário e nos espaços mais amplos da sociedade, como a Universidade.
\end{abstract}

Palavras-chave: Mulheres Camponesas, Caderno da Realidade, Espírito Santo, Permanências, Descontinuidades. 


\title{
Trajectories of peasant women in Espírito Santo: permanence's and discontinuities
}

\begin{abstract}
This article aims to understand the trajectory of peasant women in Espírito Santo from the period of 1930 to 2017, in the search for an understanding of the ways in which they lived/live and perceived/perceive their childhood, personal trajectories, insertion processes as workers and participants in the social spaces of their communities, as well as the meanings that schooling assumes throughout their lives. It uses as theoretical and methodological support Carlo Ginzburg's (1988, 1989, 2002, 2007) thinking, based on the assumptions of microhistory and the indicial paradigm, in cooperation with Mikhail Bakhtin's (2003, 2004) work, taking the narratives as concrete statements. As a source, it analyzes the narratives of four peasant women, born in Espírito Santo, materialized in the Cadernos da Realidade (Notebooks of Reality) of graduation students in Countryside Education/UFES. The analysis indicates continuities and discontinuities in the trajectories of these women in the period of investigation. As permanencies, it stands out that women still occupy domestic spaces, mainly exerting herculean activities, devoid of economic value. In addition, the patriarchal model of family/society is presented in the narratives and in the records of women from different generations. Evidence of discontinuities also emanate from the documents, such as: insertion as a child in the schooling process, the role of women in domestic services, community and wider spaces in society, such as the University.
\end{abstract}

Keywords: Peasant Women, Notebook of Reality, Espírito Santo, Permanence's, Discontinuities. 


\section{Trayectoria de las mujeres campesinas en Espírito Santo: permanencias y discontinuidades}

RESUMEN. Este texto pretende entender la trayectoria de las mujeres campesinas en Espíritu Santo, durante el período de 1930 a 2017, con el objetivo de comprender los modos como vivieron/viven y percibieron/perciben su infancia. Así como las trayectorias personales, procesos de inserción en el trabajo y participación en los espacios sociales de sus comunidades, al igual que el sentido que la escolarización asume a lo largo de sus vidas. Se privilegian los aportes del pensador Carlo Ginzburg (1988, 1989, 2002, 2007), en relación a la microhistoria y el paradigma indiciario, además de los referentes de Mikhail Bakhtin (2003, 2004), donde se toman las narrativas como enunciados concretos. Como objeto de estudio, se analizan los discursos/narrativas de cuatro mujeres campesinas nacidas en Espírito Santo materializados en los Cuadernos de la Realidad de los estudiantes de Licenciatura en Educación del Campo/UFES. Los análisis indican permanencias y discontinuidades en las trayectorias de las mujeres nacidas en esta provincia, durante el periodo investigado. Como permanencias, se destaca a la mujer ocupando espacios domésticos, sobre todo, ejerciendo actividades hercúleas, desprovistas de valor económico. Además, el modelo patriarcal de familia/sociedad se exterioriza en las narrativas y en los registros de las mujeres de diferentes tiempos generacionales. Se derivan de los documentos, indicios de discontinuidades, como: la inserción infantil en el proceso de escolarización, el protagonismo de las mujeres en el ámbito doméstico, comunitario y en los espacios más amplios de la sociedad, como la Universidad.

Palabras-clave: Mujeres Campesinas, Cuaderno de la Realidad. Espírito Santo, Permanencias, Discontinuidades. 


\section{Introdução}

A Licenciatura em Educação do Campo da Universidade Federal do Espírito Santo (doravante LEC/UFES), com habilitação em Ciências Humanas e Sociais e Linguagens, destina-se à formação de professores cujas funções de magistério deverão ser exercidas nos anos finais do Ensino Fundamental e Ensino Médio, como também em outros espaçostempos em que a diplomação dos licenciandos seja reconhecida. A LEC/UFES é um curso presencial, que assume a Pedagogia da Alternância como referência metodológica, destacando-se, nesse sentido, de acordo com o PPC do Curso, a pretensão de “... contribuir, na diversidade de ações pedagógicas, para a concretização da educação do campo como direito humano e como ferramenta de desenvolvimento social" (PPC/LEC/UFES, 2015, p. 04).

Logo, o referido Curso, tendo em vista a interlocução do conhecimento científico com os conhecimentos advindos das comunidades campesinas, intenta $\mathrm{o}$ aprofundamento das questões relativas à educação do campo pela via da reflexão conjunta, dialógica e dialética com a produção acadêmica, na perspectiva da emergência da complexidade que, nos dias atuais, tangenciam o campesinato.
Destacamos o pioneirismo do Estado do Espírito Santo na introdução da Pedagogia da Alternância no Brasil, pelo Movimento Promocional do Espírito Santo (MEPES), no Município de Anchieta. Essa pedagogia assume lugar de destaque no que se refere às problematizações a serem tecidas nos espaços formativos dos licenciandos, pois, como explicita Caliari et. al. (2013, p. 38-39, grifos do autor), “estamos convencidos de que a Pedagogia da Alternância, ao conversar com a sua realidade, as atividades desenvolvidas e o papel dela na tessitura do conhecimento, devem possuir uma afinidade e uma expressão nítida de atividades dessa própria realidade ...".

Destarte, compreendemos que salientar e problematizar os saberes e fazeres produzidos com/pelas mulheres do campo pela via da Pedagogia da Alternância torna-se efetivamente pertinente, tendo em vista que a materialização dos discursos por elas produzidos por meio dos Cadernos da Realidade nos possibilita o alcance não somente linguístico, mas principalmente dos aspectos histórico, social, cultural e ideológico que os perpassam.

Como recurso didáticometodológico, o Caderno da Realidade constitui a Pedagogia da Alternância como a materialização da mediação direta da 
realidade em diálogo com os aportes teóricos acessados. Logo, sua existência e seu uso possibilitam o acesso direto da teoria na prática, facilitando a realização da práxis em um dado contexto. A partir dessa concepção, trazemos, novamente, Caliari et al. (2013, p. 50-51) ao evidenciar o Caderno da Realidade como uma “... oportunidade de o aluno refletir sobre seu cotidiano e o quanto se encontra vinculado em seu meio...” e, para além, retratar “... a história de sua família, seu contexto social, a compreensão geofísica e econômica do meio onde vive ...".

Por conseguinte, dada a sua especificidade de desvelar a realidade paradoxalmente estranha e/ou recémdescoberta que constitui o cotidiano do estudante, o Caderno da Realidade tornase, nesse sentido, um documento, uma espécie de dossiê de informações precisas ou, por vezes, indiciárias, nos permitindo, portanto, perseguir vestígios, fios e rastros que auxiliam a visão/ação sobre a existência detectada, na possibilidade da reflexão e do agir com e diante dela, nos aproximando do verossímil, por meio de um conhecimento indireto, indiciário e conjectural (Ginzburg, 2002). Nessa perspectiva, entendemos que se torna evidente a ligação primordial dos conteúdos escolares com a realidade social do estudante por meio da mediação fornecida e materializada no e pelo Caderno da Realidade.

Mediante as considerações tecidas, entendemos que investigar a trajetória de mulheres camponesas ${ }^{\mathrm{i}}$ no/do estado do Espírito Santo entre 1930 e 2017, na perspectiva de verificar permanências e rupturas no que tange aos aspectos sociais, familiares, educacionais (escolarização), pela via do Caderno da Realidade e de narrativas dessas mulheres, torna-se não somente procedente como profícuo, uma vez que a materialidade dos discursos ali engendrados remontam a um olhar específico e, consequentemente, a uma já problematização e/ou reflexão no que tange ao diálogo entre teoria e contexto sócio-histórico.

Com esse entendimento, ao encontro do propósito maior deste trabalho ${ }^{\mathrm{ii}}$, acima explicitado, este texto objetiva, mais especificamente: a) compreender modos como mulheres camponesas capixabas viveram/vivem e perceberam/percebem sua infância e suas trajetórias pessoais; b) investigar os processos de inserção dessas mulheres no trabalho e nos espaços sociais de suas comunidades no período investigado; e c) entender os sentidos que a escolarização assume para essas mulheres, ao longo de suas trajetórias de vida.

Visando aos objetivos propostos e no sentido de balizar nossas análises, cujo 
corpus constitui-se dos discursos/narrativas de quatro mulheres materializados nos Cadernos da Realidade, trouxemos como referencial teórico-metodológico os estudos de Ginzburg (1988, 1989, 2002, 2007) e Bakhtin (2003, 2004), ao encontro da necessidade do olhar para a multiplicidade de fontes e da interrogação dos documentos para a produção da narrativa historiográfica, bem como da consideração dos Cadernos da Realidade como enunciados concretos e, nesse sentido, como gêneros discursivos. Evidenciamos também as contribuições de Cordeiro (2007), Paulilo (2009) e Neves e Medeiros (2013) tendo em vista à temática principal de nosso trabalho, as trajetórias vivenciadas por mulheres camponesas. Pensamos também que tais documentos constituem vestígios, fios e rastros (Ginzburg, 2007) para a compreensão das singularidades que caracterizam as trajetórias das mulheres capixabas, no período em análise.

Para organização do texto, elencamos três eixos/categorias as quais emergiram das fontes citadas e que guiaram nossa pesquisa, quais sejam:

- Mulheres camponesas capixabas: memórias da infância e de suas trajetórias pessoais;
- O trabalho, os desafios e inserção social das mulheres camponesas no Espírito Santo;

- Os processos de escolarização das mulheres camponesas capixabas.

Tais eixos/categorias seguem ao encontro dos objetivos de pesquisa. Logo, aspirando à organização, clareza e objetividade de nosso estudo, seguidamente, evidenciamos alguns estudos que trouxeram a mulher campesina como foco; em seção posterior, buscamos a potencialidade da temática de pesquisa, mediante um aprofundamento quanto ao referencial teórico-metodológico anunciado; e, posteriormente, damos mostras do corpus discursivo composto pelos textos materializados nos e pelos Cadernos da Realidade, os quais são analisados e discutidos como enunciados, imersos na dinâmica discursiva à qual foram produzidos.

\section{Mulheres campesinas na literatura: o campo temático da articulação entre gênero e campesinato}

Historicamente, a concepção de mulher, no contexto brasileiro, passou por diferentes modos de compreensão e idealização, tanto no âmbito doméstico, como na vida social. No Brasil colônia “... o indígena considerava a mulher uma companheira, não encontrando razão para as diferenças de oportunidades 
educacionais. Não viam, como os brancos os preveniam, o perigo que pudesse representar o fato de suas mulheres serem alfabetizadas...”, além disso, “... o trabalho e o prazer do homem, como os da mulher indígena, eram considerados equitativos e socialmente úteis..." (Ribeiro, 2011, p. 80). ${ }^{\text {iii }}$

A exploração sexual à época da colônia era intensa e abundante. Os portugueses, sustentados pelo patriarcalismo evidente e vigente, vinham para o Brasil sem suas famílias e abusavam das indígenas e das negras escravizadas. No Brasil Colônia do século XVI, o homem dominava e decidia os rumos da vida doméstica e social da família. Segundo Holanda (1995), a palavra família origina-se da expressão famulus, de origem latina, que significa: escravos domésticos de um mesmo senhor. Logo, entende-se que essa palavra e/ou expressão remete-se à obediência a um senhor patriarcal, senhor meu marido, senhor meu pai.

Nesse contexto, quando as mulheres tinham sua primeira menstruação, por volta dos 11 ou 12 anos, estavam preparadas para se casarem. Essas moças eram vigiadas o tempo todo pelo pai e os irmãos para resguardar a virgindade. A mulher era descrita como dependente e subordinada, a qual se sujeitava à dominação do pai ou do marido, tendo os afazeres domésticos como obrigação única e afastada das decisões econômicas importantes. A mulher desta época, portanto, sempre se dedicou ao espaço privado. O trabalho para ela só estava relacionado aos afazeres domésticos (Ribeiro, 2011).

Refletir sobre a história das mulheres no Brasil é, inevitavelmente, abordar os modos como viveram no campo, pois, até o início do século XIX o Brasil constituía-se em um enorme país rural. O estilo de vida da elite dominante na sociedade brasileira era marcado por influências do imaginário da aristocracia portuguesa, do cotidiano de fazendeiros plebeus e das diferenças e interações sociais definidas pelo sistema escravista e determinada pelo total patriarcalismo. A chamada família patriarcal brasileira, comandada pelo pai detentor de enorme poder sobre seus dependentes, agregados e escravos, habitava a casa-grande e dominava a senzala (D'incao, 2004).

Sabemos dos desafios da escrita sobre a História das mulheres, tanto pelo forte machismo que predomina em nossa sociedade, como pelo lugar social secundário que a mulher ocupou e, não raro, ainda ocupa em muitas comunidades. Desse modo, tratar da história de mulheres já se constitui em um esforço necessário e, por se tratar de mulheres camponesas 
capixabas, essa tarefa é ainda mais profícua, pois a historiografia deste estado tem sido foco de pesquisas atuais, mas ainda demanda de muitos esforços historiográficos no sentido de tatearmos as semi-invisibilidade da História do Espírito Santo (Simões \& Franco, 2004).

Somamos a esses desafios o fato de abarcarmos a trajetória de mulheres camponesas, tema que tem ocupado o lugar da invisibilidade social em pesquisas (Neves \& Motta-Maués, 2013). De acordo com Neves e Motta-Maués (2013), dentre os lugares-comuns nas interpretações de muitos autores que se ocupam de formas de ação das mulheres no campesinato, há a exaltação de que elas realizam tarefas hercúleas, desempenham papel fundamental na posição de defesa da posse da terra ou até mesmo em movimentos diante da sua expropriação, no entanto, muitas vezes, não têm essas tarefas reconhecidas por seus respectivos valores sociais e econômicos.

Desse modo, corroborando o pensamento de Del Priori (2004), interrogamos: teria então chegado o tempo de falarmos, sem preconceitos, sobre as mulheres? Teria chegado o tempo de lermos, sobre elas, sem tantos a priori? Muito se escreveu sobre a dificuldade de se construir a história das mulheres, mascaradas que eram pela fala dos homens e ausentes que estavam do cenário histórico. Acreditando que essa discussão não está superada, o presente estudo constitui-se em ponto de partida para investigações que tenham como foco as mulheres camponesas no Espírito Santo. Portanto, temos como objetivo visibilizar, pela via dos registros e discursos dos Cadernos da Realidade, trajetórias das mulheres camponesas de comunidades capixabas.

\section{O que os estudos sobre mulheres camponesas no Brasil apontam?}

Ao inventariar o campo temático da articulação entre gênero e campesinato, Neves, Santos e Cruz (2013) apontam para a invisibilidade social das mulheres em produções acadêmicas $^{\text {iv }}$. Tal ocorrência é geralmente explicada pela dominação masculina, por vezes em absoluto, dada a referência à tão hegemônica influência masculinizante de regras e organização institucionais; ou defendida por filiações e cumplicidades políticas dos pesquisadores com o repúdio à submissão de mulheres; ou por investimentos fundamentados em construção de denúncias como parte dos procedimentos políticos de mudança nas respectivas relações de poder. A respeito dessa invisibilidade social e os riscos de considerá-la nas interpretações e análises, os autores asseveram: 
Se a invisibilidade social pode ser entendida pela impossibilidade de participação na vida pública ou pelo irreconhecimento do papel ativo das mulheres no processo de elaboração da vida social, aceitá-la como princípio de interpretação é se colocar diante da exigência de, no mínimo, explicar, em cada situação, como se define a vida pública e a respectiva organização social (Neves, Santos \& Cruz, 2013, p. 351-352).

Ao analisar o conjunto de estudos a respeito de gênero no espaço rural, Neves, Santos e Cruz (2013) alertam para a escassez de pesquisas preocupadas com as mudanças recentemente vividas na organização social e ideológica do mundo ocidental que vieram a interferir na vida familiar e nos papéis até então atribuídos às mulheres, no caso, camponesas. Constatam, portanto, significativa “... ausência de interpretações sobre a metafórica transformação qualificada como revolução social, em face das alterações provocadas nas relações entre os sexos, bem como pelos deslocamentos sociais nesses termos operados" (Neves, Santos \& Cruz, 2013, p. 352).

Em termos quantitativos, Neves (2013) faz o levantamento de 12 estudos, entre dissertações e teses defendidas em programas de Pós-Graduação no país, entre 1995 e 2007, tematizando analiticamente relações de gênero no mundo rural. Desse total, 3 trabalhos interessam-nos especialmente (Oliveira, 2007; Janata,
2004; \& Brochado, 1998 apud Neves, 2013) por tratarem da mulher no espaço rural.

Neves (2013) analisa a dissertação de mestrado em Educação da Universidade Federal da Paraíba, defendida em 2007 por Maria Lucia Lopes de Oliveira, que toma como espaço físico e social de análise um assentamento no Cariri Paraibano. A pesquisa teve como objetivo principal identificar as transformações ocorridas no cotidiano das mulheres em assentamentos rurais. Abarca relações pessoais e coletivas, consideradas mediante $\mathrm{o}$ reconhecimento da vivência de mulheres em processos de empoderamento e sob um trabalho interventivo, pautado na formação feminista proposta pelo Coletivo Feminista e pelo Centro da Mulher 8 de Março.

Os resultados mais evidentes destacados pela autora foram: elevação da autoestima; exercício da fala nos espaços públicos; reconhecimento social de saberes que dominam; e respectivo enriquecimento decorrente de novos conhecimentos no desenvolvimento de suas habilidades práticas. Tais aquisições materiais, mas principalmente de símbolos de prestígio, segundo a autora, facilitaram: o acesso às políticas de crédito; o reconhecimento da identidade de trabalhadora rural; a consciência crítica das desigualdades de poder que referenciam relações entre 
mulheres e homens e os padrões de organização social (Neves, 2013).

Outro estudo analisado por Neves (2013) intitula-se Fuxicando sobre a cultura do trabalho $e$ do lúdico das meninas-jovens-mulheres de assentamentos do MST. Trata-se de dissertação de mestrado em Educação Física da Universidade Federal de Santa Catarina, defendida em 2004 por Natacha Eugênia Janata.

Neves (2013) aponta que a investigação se circunscreveu ao estudo da articulação entre a atividade de educação física e a produção de engajamentos em Movimentos Sociais, particularmente no Movimento dos Trabalhadores Rurais Sem Terra (MST). Partindo da problemática da migração da juventude rural para a cidade, o objetivo de Janata (2004) foi compreender as relações e contradições entre a cultura do trabalho e a cultura lúdica, vividas e construídas pelas jovens dos Assentamentos 30 de Outubro e São José. Ambos são representantes de mobilizações coordenadas por lideranças do MST e estão situados no município de Campos Novos-SC.

Janata (2004), ao valorizar a participação das mulheres nas atividades de pesquisa participativa, traz ao conhecimento do leitor a explicitação situacional de sonhos. Por essa reflexão coletiva, as mulheres adquiriram um novo significado diante dos engajamentos no projeto político do MST (Neves, 2013).

No contexto de estudos agrários, com enfoque em questões vinculadas às condições de trabalho e a reprodução da vida de seres humanos, Ofélia Cerinéia Brochado, mestre em Geografia (Humana) em 1998 pela Universidade de São Paulo, no texto Trabalho, Saúde e Reprodução da Vida: A mulher boia-fria no mundo cindido de Paraguaçu Paulista, considera o trabalho volante feminino em áreas agrícolas canavieiras do país. Ao enfatizar a participação das mulheres, a autora reivindica sua afiliação aos estudos de gênero, dimensionando as condições de existência da mulher cortadora de cana, sujeito de dupla exploração: como mulher e como trabalhadora (Neves, 2013).

Além dos 3 trabalhos selecionados a partir do levantamento de Neves (2013), localizamos e analisamos 2 estudos que nos permitem uma aproximação do cotidiano de mulheres camponesas e dos desafios enfrentados pelas mesmas nos espaços domésticos e sociais, considerando as relações assimétricas que se estabelecem nesses espaços. Trata-se do artigo Movimento das Mulheres Agricultoras e os muitos sentidos da "igualdade de gênero", publicado por Paulilo em 2009, e do artigo intitulado: Gênero em contextos rurais: a 
liberdade de ir e vir e o controle da sexualidade das mulheres no Sertão de Pernambuco, de autoria de Cordeiro (2007).

Paulilo (2009) partiu do pressuposto de que as mulheres, ao participar de movimentos coletivos, sejam elas feministas ou não, tendem a questionar sua posição social subordinada. Para tanto, a autora entrevistou mulheres militantes e não militantes e procurou perceber se esses questionamentos de gênero estavam pondo em xeque a identidade entre os interesses femininos e os dos outros membros da família.

$\mathrm{O}$ interesse da autora remeteu-se principalmente à busca pelas diferenças entre 0 discurso das mulheres do Movimento de Mulheres Camponesas e o das líderes de outros movimentos, tendo como contraponto o discurso das não militantes de três estados do Sul, especialmente em Santa Catarina.

Os resultados do estudo de Paulilo (2009) apontam para o fato de que somente quando as mulheres começarem a questionar o casamento tradicional é que questionarão o fato de ele ser a única via para a profissão de agricultora. A questão da não-herança da terra é ainda um tabu entre as mulheres rurais. Segundo essa autora, pedir igualdade de gênero nas políticas públicas parece ser mais fácil que enfrentar a questão dentro da família. Sem dúvida, a oposição a grupos que não são próximos afetivamente e que, portanto, podem ser caracterizados como "inimigos", traz menos desgaste emocional que se oporem a maridos, pais, sogros, irmãos e filhos homens.

O estudo de Cordeiro (2007) objetivou compreender as restrições e os obstáculos de gênero à liberdade de ir e vir das lideranças e participantes do Movimento de Mulheres Trabalhadoras Rurais do Sertão Central de Pernambuco (MMTR), tendo como hipótese norteadora que na restrição ao ir e vir das mulheres também se consubstancia o controle da sexualidade feminina. A autora dialogou com as ideias de Foucault (2004) sobre moral e sexualidade, com as reflexões feministas sobre gênero (Scott, 1991) e o referencial das práticas discursivas e produção de sentidos no cotidiano (Spink, 1999).

Cordeiro (2007) destaca que as pesquisas sobre a agricultura familiar tendem a assinalar $\mathrm{o}$ padrão rígido $\mathrm{e}$ assimétrico das relações de gênero na área rural, ressaltando que, muitas vezes, as mulheres são confinadas ao espaço da casa, do roçado e da comunidade onde moram, defrontando-se com ordens morais de gênero que impõem duras restrições ao ir e vir. 
A autora destaca que apesar das transformações na área rural e da superação do debate sobre o mundo rural e o mundo urbano como instâncias isoladas, o controle e a regulação das condutas e dos corpos das mulheres constituem elementos importantes nas ordens morais de gênero. E a família, parentes, vizinhos e a comunidade exercem vigilância para que assim continue. Ficar 'falada', 'malfalada', ser alvo dos 'olhares' 'de alguém reparando' são algumas das artimanhas a que homens e mulheres recorrem para impor sanções, coerções ou dificultar as “escapadas" e "piscadelas" das mulheres.

Os estudos acessados permitem-nos uma aproximação do que se tem produzido, em âmbito nacional, a respeito das mulheres camponesas, ao apontar para a invisibilidade das mulheres na produção de estudos sobre seus próprios contextos de vida, a pouca representatividade no que tange seu papel econômico e social nas comunidades em que vivem. Ademais, destacaram desafios na busca por igualdade de gênero nas políticas públicas e nos espaços domésticos e a constatação de que o controle e a regulação das condutas e dos corpos das mulheres constituem-se elementos importantes nas ordens morais de gênero.

$\mathrm{Na}$ busca por estudos desenvolvidos no Espírito Santo, acessamos o banco de dados do Programa de Pós-Graduação em Educação (PPGE) e em História (PPGHIS) da Universidade Federal do Espírito Santo. Localizamos 5 estudos que tomam como temática a mulher (Siqueira, 2008; Rangel, 2011; Suanno Neto, 2014; Silveira, 2015; e Rocha, 2016), porém, nenhuma das pesquisas localizadas tematiza mulheres camponesas. Tal constatação indicia a importância dessa reflexão inicial, constituindo-se como ponto de partida para estudos que focalizem a mulher camponesa capixaba e suas trajetórias de vida.

\section{Discursos e memórias de mulheres campesinas do Espírito Santo: os enunciados concretos materializados nos Cadernos da Realidade}

Neste momento de nosso estudo, damos a conhecer narrativas de mulheres campesinas do Espírito Santo, transcritos dos Cadernos da Realidade de estudantes da LEDOC/UFES, objetivando a problematização de tais discursos tendo em vista nosso principal objetivo de pesquisa: refletir acerca da trajetória de mulheres camponesas $^{\mathrm{v}}$ no/do Espírito Santo na perspectiva de verificar permanências e descontinuidades no que tange aos aspectos sociais, familiares, educacionais (escolarização) no período de 1930 a 2017.

Torna-se importante explicitar que os discursos foram elencados tendo em vista o delineamento da temática e objetivos de 
pesquisa e, mediante tal direcionamento, a possibilidade de abrangência do recorte temporal explicitado. Nessa perspectiva, entendemos com Ginzburg (2007, p. 287) que "... devemos aprender a desembaraçar os fios multicores que constituem o emaranhado do contexto investigado".

Logo, a seleção de Helena, Vanilda, Dória e Karina contando, consecutivamente, com 92, 85, 81 e 21 anos, elencadas pela possibilidade de representar as continuidades e descontinuidades existentes neste processo histórico: a mulher do presente - 21 anos e a mulher do passado, em diferente fases/momentos - 92, 85 e 81 , visou traduzir a potência da narrativa da mulher campesina, com vistas à potencialidade do período investigado.

Nessa perspectiva, prosseguimos com o estudo dando a conhecer as narrativas das referidas mulheres, com vistas aos três eixos/categorias elencados:

- Mulheres camponesas capixabas: memórias da infância e de suas trajetórias pessoais;

- O trabalho, os desafios e inserção social das mulheres camponesas no Espírito Santo;

- Os processos de escolarização das mulheres camponesas capixabas.

\section{Mulheres camponesas capixabas: memórias da infância e de suas trajetórias pessoais}

A princípio, dedicamos este texto às memórias de infância narradas por mulheres capixabas e, também, reminiscências de suas trajetórias particulares desencadeadas em seus processos sociais, levando em conta que compreendemos, conforme explicita Bakhtin (2004, p. 58 grifos do autor), que

.. o conteúdo do psiquismo
individual é, por natureza, tão social
quanto a ideologia e, por sua vez, a
própria etapa em que o indivíduo se
conscientiza de sua individualidade e
dos direitos que lhe pertencem é
ideológica, histórica, e internamente
condicionada por fatores
sociológicos...

Logo, ao narrar às memórias de infância, as mulheres campesinas trazem à tona os contornos históricos e sociais imanentes à sua época.

Paralelamente ao pensamento de Mikhail Bakhtin (2003, 2004), buscando os indícios por meio de detalhes quase invisíveis e, por vezes, negligenciados, Ginzburg (2007) sustenta seu método historiográfico ao retirar o véu macrohistórico que esconde detalhes importantes das minorias.

O que dizer de indivíduos pouquíssimo estudados? Como narrar histórias de reclusão e repressão 
historicamente negligenciadas? $\mathrm{O}$ que pensar destas mulheres na atualidade em comunidades capixabas? Nesse ínterim, deve-se levar em conta “... que o acúmulo do conhecimento sempre ocorre assim: por linhas quebradas em vez de contínuas; por meio de falsas largadas, correções, esquecimentos, redescobertas; graças a filtros e esquemas que ofuscam e fazem ver ao mesmo tempo" (Ginzburg, 2007, p. 111).

Nesse caminho, Bakhtin (2004) acredita que nossa consciência surge e se afirma por meio dos contextos vividos, de modo que emergem, nos discursos das mulheres aqui visibilizadas, modos de pensar, viver e de rememorar suas experiências nos espaços/tempos domésticos, sociais, políticos, econômicos e culturais.

Narrativas a respeito das reminiscências de infância das mulheres camponesas revelam diferentes facetas, permeadas por desafios, superações e dificuldades que impactam na constituição de suas famílias e em suas singularidades. É o que se indicia nas narrativas de Dória, que viveu a infância nas décadas de 1930 e 1940:

Eu nasci em uma casa muito ruim. Já morei em tantas casas ... mais de 20 casas .... Eram casas muito ruins, paiol mesmo. Nós éramos muito pobres. Éramos em 11 irmãos e precisávamos trabalhar muito. Meu pai bebia muito. Uma vez ficamos todos doentes com sarampo e minha avó trazia um pouco de leite com arroz para nós comermos. Éramos muito pobres. Eu só tinha dois vestidos, que eu vestia dia de quarta-feira e sábado. Meu pai não trabalhava, só bebia (Dória, 81 anos) ${ }^{\mathrm{vi}}$.

Vivendo a infância na década de 1920, Helena destaca condições materiais que marcaram seu cotidiano. Em suas palavras: "O colchão era feito de palha de milho, o travesseiro de pena de galinha e o cobertor de pendão de taboa. Era uma época muito difícil, mas eu daria tudo pra voltar lá ...”(Helena, 92 anos).

Helena prossegue seu relato acionando suas memórias lúdicas. Detalha brincadeiras e modos de produzir artefatos para os momentos de diversão, compartilhados com seus irmãos:

... as brincadeiras que a gente fazia eram só durante o dia, porque à noite não tinha energia, era uma escuridão medonha. Tinha um terreiro enorme que era para secar o café e ali a 'gente' brincava... brincava de chicotinho queimado e de 'roda'. Nós éramos em 4 irmãos, onde brincávamos nós quatro, porque morávamos numa casa isolada. Tinha uma cachoeira muito bonita, hoje não tem mais nada porque já secou. Os brinquedos que tínhamos para brincar na época era peteca que se fazia de palha de milho e bola que nós fazíamos de pano. A 'gente' pegava pano velho, enrolava, enrolava $\mathrm{e}$ amarrava com cordão de banana para formar uma bola. Assim, brincávamos de tarde (Helena, 92 anos). 
Encontramos a presença de brincadeiras e momentos de diversão na infância de Karina, ao relatar suas memórias dos anos 2000: “A 'gente' brincava muito de pique esconde, piquepega, pique-bandeira. Eu também gostava muito de brincar de carrinho junto com meus primos e vizinhos de perto. A principal brincadeira era construir estradinhas na 'barreira' e fazer caminhos, fazer cerquinhas para carrinho" (Karina, 21 anos).

Ao compreendermos que “... há figuras do passado que o tempo aproxima em vez de afastar" (Ginzburg, 2007, p.53), interrogamos, a partir das narrativas das mulheres aqui presentificadas: o que marca a infância das mulheres camponesas no Espírito Santo? Ao considerarmos as depoentes que foram crianças nas décadas de 1930 e 1940 e a que viveu a infância nos anos 2000, quais permanências marcam suas trajetórias? Que descontinuidades observamos? Até aqui, ouvimos relatos marcados pelas condições econômicas desfavoráveis e os desafios de uma vida familiar com a presença de um pai alcoólatra, que certamente incumbia à mãe o sustento da família. Por outro lado, há discursos permeados por momentos de alegria e diversão, em que as experiências lúdicas ganham espaço nas memórias e nas narrativas das mulheres, que, ao acessar as camadas do passado, retém objetos que são, para elas, e só para elas, significativos dentro de um tesouro comum (Bosi, 1987).

Em muitos momentos, as narrativas da infância confundem-se com a inserção dessas mulheres nos espaços/tempos de trabalho. É o que relatou Karina: "Eu cresci indo pra roça, cresci tendo minha peneirinha, tendo minha enxadinha, meu rastelinho, molhando plantinhas. Cresci junto no dia a dia da minha família, indo pra lavoura. Eles têm café, banana, uma propriedade muito diversificada, apesar de ser pequena" (Karina, 21 anos). Nessa mesma ótica, Vanilda, referindo-se a experiências vividas há mais de 50 anos, revela:

... meu pai só queria que nós trabalhássemos. Com 8 anos já íamos para a roça. Às vezes falávamos que íamos embora porque tinha muito mosquito, aí meu pai falava: 'vocês vão embora porcaria nenhuma! Vocês não querem comer? Não querem beber? Então vão trabalhar" (Vanilda, 85 anos).

Notamos o pesar nas falas de Helena, ao mencionar que o trabalho ocupou muito espaço em sua vida, sobretudo na adolescência:

Quase não aproveitei minha adolescência, eu tive que trabalhar muito, depois que chegava da escola ia para casa de uma vizinha lavar louças. Depois ia para minha casa ajudar minha mãe a lavar roupas e passar com o ferro à brasa, pois não 
tinha energia ainda. Eu estava sempre fazendo bordados e outros trabalhos artesanais (Helena, 92 anos).

Emerge, por meio dos discursos evidenciados, uma possível demarcação de uma fase da adolescência da mulher do campo, até aproximadamente os anos de 1940, marcada pelo trabalho doméstico e, consequentemente, pelo preparo dessa menina-mulher para o casamento, estimado, em grande parte, como o único destino possível e viável, sendo que a possibilidade de educação formal e/ou escolarização encontrava-se à margem de suas expectativas. Vemos, assim, a narrativa, em uma perspectiva bakhtiniana, carregada de sentido ideológico ou vivencial e capaz de trazer consigo a realidade e a vida de seu locutor, traduzindo suas diferentes matizes (Bakhtin, 2004).

Portanto, o casamento precoce parece-nos, parafraseando Ginzburg (1989), um indício eloquente de permanências nas trajetórias narradas pelas mulheres camponesas aqui focalizadas. É o que relatam Dória: "Com 18 anos conheci meu marido ele nos ajudou, pois meu pai tinha morrido. Me casei e morei em vários lugares... Ele não trabalhava na roça, nós não tínhamos roça" (Dória, 81 anos), e Vanilda:
Conheci meu marido em Venda Nova. Ele trabalhava com tropa. Me casei com 17 anos e vim morar em Ponto Alto, Domingos Martins com ele. Começaram a chegar os meninos, então ele viu que trabalhar com tropa não dava mais, pois eu ficava sozinha. Então nos mudamos para Perobas, onde estou até hoje (Vanilda, 85 anos).

A narrativa de Karina aponta pistas a respeito de práticas permanentes nas trajetórias das mulheres camponesas: o casamento precoce e, simultaneamente, descontinuidades, como o acesso e conclusão da escolarização básica:

Sobre namoros, tive algumas paqueras, alguns relacionamentos, mas namoro de verdade só tive um, que foi com meu colega de escola que eu conheci lá em 2008 na $5^{\text {a }}$ série e estudei com ele nesses 4 anos. Depois estudamos mais 4 anos juntos na Escola Família Agrícola de Olivânia, mas só no finalzinho do $3^{\circ}$ ano do Ensino Médio que a gente começou mesmo a se relacionar. Então no final do $4^{\circ}$ ano do Ensino Médio eu engravidei, aí tive o meu filho, o A. V. Eu tinha 19 anos quando eu ganhei o A. Mais tarde, quando o A. já tinha 9 meses, a gente se casou no civil e no religioso, a gente está casado há 1 ano e meio (Karina, 21 anos).

Ao compreendermos as narrativas enquanto textos que, ao serem interrogados, nos possibilitarão conjecturarmos acerca dos modos como as mulheres camponesas construíram suas trajetórias, como Ginzburg (2007), buscamos escavar os meandros dos textos, 
fazendo emergir vozes incontroladas. Portanto, interrogamos: Quais seriam as motivações que conduzem aos casamentos precoces das mulheres aqui focalizadas? Estariam relacionadas à constatação de Paulilo (2009) de que o meio rural não seria um bom lugar para as solteiras, tendo em vista que a condição do celibato laico, camponês e feminino, constitui-se por "recusas, retenções e negações" (Rodrigues, 1993 apud Paulilo, 2009, p. 192)? Mesmo com a ausência de respostas nas narrativas encontradas, acreditamos que a interrogação pode provocar outras possíveis narrativas e escritas das próprias mulheres em busca de respostas para estas [e outras] indagações.

Marcas do machismo e da submissão feminina presentificam-se nas narrativas de Dória, quando relata momentos conflituosos com o cônjuge: "Eu e meu marido às vezes brigávamos. Quando ele era novo andava com [outras mulheres] e eu ficava em casa, mas eu não o xingava. Não adiantava, né? Quanto mais briga pior fica, né? Mas nunca deixou faltar nada em casa" (Dória, 81 anos).

O relato de Dória, que reflete a experiência vivida na década de 1950, aponta para um modelo de família patriarcal propagandeado e, em muitos aspectos, observados nas famílias brasileiras. O lugar da mulher e do homem estava claramente demarcado, como mostra Bassanezi (2004), ao discutir o papel da mulher nos anos dourados (1950), por meio de periódicos femininos do período $^{\text {vii }}$. A autora alerta que o conteúdo veiculado nas revistas não revelava que todas as mulheres pensavam e agiam de acordo com o esperado, mas indicava as expectativas sociais que faziam parte de sua realidade, influenciando suas atitudes e pesando em suas escolhas.

Desse modo, ao apontar como os periódicos tratavam a infidelidade feminina e masculina, observamos as disparidades. Em relação à mulher, em primeiro lugar, a autora destaca que esse tema não era recorrente nas revistas do período. Ademais, quando aparecia, as mulheres “... eram aconselhadas a controlarem suas frustrações, fugirem das tentações e, dominando seus impulsos, manterem-se fiéis aos maridos, mesmo que eles não agissem do mesmo modo". E acrescenta: "O remorso, a vergonha moral e os riscos de perder o marido, os filhos e o respeito social não compensariam o prazer enganoso e fortuito da aventura extraconjugal" (Bassanezi, 2004, p. 530531). Por outro lado, a infidelidade masculina assume tratamento distinto:

Se o marido infiel mantivesse minimamente as aparências e continuasse provendo sua família com bens materiais, as esposas não 
deveriam se queixar. Afinal, a infidelidade masculina justificava-se pelo temperamento poligâmico dos homens - um fator natural que, mesmo quando considerado uma fraqueza, merecia a condescendência social e a compreensão das mulheres. Paciência e sacrifícios, integridade e determinação para manter a integridade da família (Bassanezi, 2004, p. 531).

Os apontamentos de Bassanezi (2004) a respeito dos modos como se pensava o comportamento das mulheres nas famílias e na sociedade, nos anos de 1950, se aproximam de situações vividas no mesmo período por Helena:

Em 1957 foi construída a igreja católica na comunidade. $\mathrm{Eu}$ era luterana e J. católico. Aí um pastor falou pra mim: duas religiões numa casa não dá certo porque se o pai tem uma religião e a mãe tem outra, os filhos ficam perdidos, não sabem se vão para cá ou se vão para lá. Então, eu pensei bem, eu sou mulher eu tenho que ceder. Aí passei para a religião dele (Helena, 92 anos, grifos nossos).

A partir da escuta e do diálogo com as narrativas aqui privilegiadas, reconhecemos, ainda hoje, traços nos modos como as mulheres são pensadas e os lugares que ocupam nos espaços domésticos e sociais. Concordamos com o pensamento de Bassanezi (2004, p. 533): "Permanecem certos costumes e valores que definem, unem ou separam e até estabelecem hierarquias entre homens e mulheres". Por outro lado, muitas das ideias e das práticas observadas nas décadas de 1930 a 1950 foram contestadas e superadas, podendo, nos dias atuais, causar reações do estranhamento a repulsa.

\section{A inserção das mulheres camponesas nos espaços sociais e no trabalho}

Pela via das memórias de infância narradas, evidenciamos que o trabalho sempre fez parte da vida das mulheres camponesas capixabas desde a infância. Ora o trabalho em casa, nos afazeres domésticos, ora o trabalho na lavoura, auxiliando na subsistência familiar e, não raro, a concomitância de ambas atividades laborais faziam-se e, quiçá, fazem-se presentes no(s) cotidiano(s) dessas mulheres.

Ao encontro desse desvelamento, encontramos Del Priore (2004, p. 54), explicitando que:

As experiências de vida relatadas pelas mulheres rurais mostram que em seu cotidiano não há uma clara distinção entre os limites do lar e do trabalho, entre as atividades domésticas e as tarefas agrícolas, entre as responsabilidades na educação dos filhos e a vida comunitária. No campo, a autoridade do chefe de família - do pai ou do marido - extrapola o espaço doméstico e muitas vezes impõe-se, negando a participação das mulheres nas decisões nas cooperativas, nos bancos, nas associações de produtores e nos sindicatos. 
Acerca da dupla e/ou tripla jornada de trabalho da mulher campesina capixaba, a narrativa de Karina aponta que:

No ambiente de trabalho não sofri nenhuma discriminação porque onde a gente mora e trabalha a gente vive de maneira bem igual de um para o outro, apesar de que a mulher tem uma dupla jornada de trabalho. Se ela vai para a lavoura ainda tem que cuidar da casa eu vejo isso, por exemplo, na família da minha sogra e também na família da minha mãe. Se vai pra roça, ela ainda volta pra casa, tem que dar conta da comida, tem que dar conta da casa arrumada e é muito cobrada por isso. Já na minha relação com meu marido a gente não tem isso, porque que se eu for ajudar, ele também me ajuda. Em casa, é ele que faz a janta e também me ajuda com as roupas e com nosso filho, me ajuda com tudo não tem esta discriminação, esse preconceito dentro de casa. Mas eu vejo isso muito nos vizinhos, também na minha família mesmo. $\mathrm{Na}$ comunidade de modo geral o que eu percebo é essa dupla jornada de trabalho ou às vezes tripla que às vezes a mulher tem, que é o homem que quer que ela vá para a roça, quer que ela ajude, mas quando volta, ela que tem que arrumar a casa, ela que tem que fazer todo o serviço de casa e dar conta da alimentação ainda (Karina, 21 anos)

Podemos considerar, a partir do que indicia $o$ discurso de Karina, a continuidade de um período exaustivo de trabalho diário da mulher camponesa capixaba, no entanto, a narrativa também evidencia uma possibilidade de ruptura no que tange à participação masculina nas tarefas domésticas e, nesse sentido, tanto um reconhecimento do labor exaustivo da mulher camponesa, como também de que algumas tarefas não se restringem unicamente ao universo feminino, na direção, pois, de uma relação mais igualitária e justa entre os pares.

Todavia, as narrativas também nos permitem inquirir: até que ponto o trabalho permitiu e/ou ensejou a inserção das mulheres camponesas nos espaços sociais do campo, com atuação significativa no que tange às suas pautas reivindicatórias?

"Começamos a trabalhar com cana, milho e feijão, trabalhávamos de manhã à noite, naquela época não tinha energia, ligava a lamparina e ia tratar de porco, tínhamos muito porco" (Vanilda, 85 anos). "Eu sou lavradora e tenho esta profissão principalmente por causa da minha família" (Karina, 21 anos). As duas narrativas, de tempos geracionais diversos, nos remetem, de certa forma, a uma possibilidade de participação na vida social $\mathrm{da}(\mathrm{s})$ comunidade(s) campesina(s) pelo duto do trabalho agrícola. No entanto, retomando a colocação de Del Priore (2004) e trazendo o prosseguimento das narrativas, compreendemos que tal participação demandou enfrentamento e disposição para sua efetivação, principalmente tendo em vista a inserção em diferentes frentes de trabalho, que não a doméstica e na lavoura: 
Comecei a trabalhar, trabalhei alguns meses em Campinho, aí fui convidada para dar aula aqui em Perobas porque a professora que dava aula aqui só vinha 3 meses e ia embora pois aqui era uma tapera, não tinha nada, então vim. Chequei aqui dia 28 de fevereiro de1945, uma escuridão, só se via a estrada quando relampeava, meu pai me trouxe, fiquei numa casa antiga com um varandão. Quando acordei no outro dia pensei assim, não vou ficar aqui não! Isso aqui era um brejo, você tinha que ter cuidado para andar, aqui não tinha nada, só tinha duas casas, a do senhor T. que já foi demolida e do P. T., meu sogro. Aí falei com meu pai que não ia ficar aqui, meu pai falou: experimenta uma semana, se você gostar você fica, se não gostar você vai pra casa. Como eu já tinha uma conversinha com J., eu fiquei de uma semana já se vão 72 anos (Helena, 92 anos).

A narrativa de Helena, destacando sua trajetória como professora, revela as questões que permearam sua inserção em uma profissão marcada, até mesmo nos dias atuais, pela presença feminina e, para além, os aspectos que perpassam tal atividade no contexto de uma comunidade campesina:

Naquela época era muito difícil dar aula, trabalhava com as quatro séries juntas, eu passava o exercício pra um, aí o outro conversava, atrapalhava, aí eu fiz o seguinte, dividi o $1^{\circ}$ e o $2^{\circ}$ de um lado e o $3^{\circ}$ e o $4^{\circ}$ do outro lado. Coloquei um quadro negro de cada lado, ai não dava tempo deles conversarem e brincarem. Não existia merenda escolar, nem material escolar, tinha um aluno que era muito pobre, não tinha o que comer, ele vinha para a escola e ficava de cabeça baixa na carteira, de fraqueza. Aí eu pensei: meu Deus, este menino desse jeito não pode ficar. Aí eu levava pra ele de manhã uma merenda, às vezes eu levava pão de casa com ovo, dava para ele comer para poder estudar. $\mathrm{O}$ recreio era meia hora, eu cantava roda para eles, brincavam de jogar lenço, chicotinho queimado umas brincadeiras muito bonitas. (Helena, 92 anos).

Na compreensão do que nos expõe Helena, entendemos com Bakhtin (2003, p. 312), que "a atitude humana é um texto em potencial e pode ser compreendida (como atividade humana e não ação física) unicamente no contexto dialógico da própria época (como réplica, como posição semântica, como sistema de motivos)". Logo, podemos inferir que a atividade humana, aqui traduzida pela atividade laboral, evidencia-se como forma de inserção das mulheres camponesas nos espaços sociais, assim como a efetividade de participação em tais espaços pode ratificar e dar visibilidade ao trabalho realizado.

É com essa perspectiva que enfatizamos a narrativa de Vanilda (85 anos), no que tange, principalmente, ao empenho no desenvolvimento de uma atividade humana cuja realização evidencia a relação direta e implicada com $\mathrm{o}(\mathrm{s})$ espaço(s) sociais campesinos:

Meu pai me ensinou a benzer quando tinha 15 anos e até hoje eu trabalho com isso, já vivi preconceito por ser 
benzedeira pelo pessoal da igreja católica, mas o que falo é a palavra de Deus, mas eu faço de bom coração e enquanto eu tiver viva eu não vou desistir, pois com 85 anos hoje eu não vou desistir, não vou mesmo, pois se fosse palavra ruim, troço ruim ai sim o pessoal podia falar mais é tudo palavra de Deus. Todo dia tem gente aqui, tem dia que tem 13 , tem 15 até 20 pessoas e eu enfrento tudo na Fé de Deus e graças a Deus tá dando tudo certo, e eu não vou desistir enquanto eu tiver vida, não vou desistir porque não é palavra ruim é palavra de Deus (Vanilda, 85 anos).

A narrativa de Vanilda traz um homem (pai) e uma mulher (filha) exercendo a mesma prática, no entanto percebidas de modos distintos pela comunidade campesina: para o homem, a aceitação e o reconhecimento; para a mulher, a despeito do usufruto de sua atividade, o julgamento. Pensamos, portanto, na perspectiva ginzburgniana (1988), ao investigar processos inquisitoriais, pois traz a mulher como um dos sujeitos centrais, acusada de bruxaria. Neste espaço de pesquisa, Vanilda assumiria o lugar da bruxa, que, por meio dos inguentos, oferece a cura aos sujeitos do campo, já o pai, tem sua integridade moral preservada e sua atividade valorada no contexto social mais amplo da comunidade.

As narrativas destacadas podem confirmar uma inserção e participação gradativas e não facilitadas da mulher camponesa capixaba nos espaços sociais e, em uma via de mão dupla, em atividades de trabalho que não sejam as domésticas e agrícolas, transparecendo, pois, em um exercício de afinco e de manifestação de interesse e desejo de participação nesses espaços. Como nos releva Karina (21 anos):

Eu participo muito da igreja e da vida social da comunidade, vou à igreja todos os domingos, mas também participo de festas, outras coisas que acontecem na comunidade, ajudo a organizar, tenho minhas responsabilidades. Nas escolas, quando eu estudava, eu participava também do 'corpo' da escola. Eu conheci bastante o sindicato dos trabalhadores rurais de Domingos Martins, porque meu pai trabalhava lá. Ele trabalhou 10 anos, então quando trabalhava lá a gente sabia de lá e tal, e participava das coisas que o sindicato fazia. Hoje sou membro sócia do sindicato... (Karina, 21 anos).

Cotejando as narrativas de Vanilda e Karina, quanto à participação nos espaços sociais das comunidades campesinas, encontramos a permanência de um desejo de atuação nesses espaços, os quais, independentemente do teor/modos como se materializam acabaram por trazer para si diferentes matizes e formas de materialização do preconceito:

E como eu me percebo como mulher na sociedade: já sofri preconceito na família mesmo, tipo na geração do meu avô. Ele é uma pessoa que é 
característica desta sociedade machista, por exemplo, estes dias mesmo, eu sou mulher e tenho um irmão D. e uma irmã A. e a gente foi para uma cavalgada e eu queria ir em determinado animal. Aí meu avô disse: não, aquele lá você não sabe montar, tem que ser homem para montar naquele. Aí foi assim, me deixou constrangida, meio triste também por ouvir isso dele. Mas, já em relação aos meus pais, eles já são de uma geração diferente eles sempre me trataram e meus irmãos de maneira muito igual. Se eu ia para a roça, o D. também ia, a A. também ia, é claro que cada um tem suas limitações, mas eles sempre nos viram como pessoas iguais, independente do sexo de cada um (Karina, 21 anos).

$\mathrm{Na}$ perspectiva das narrativas destacadas, compreendemos que, a despeito da(s) vicissitudes no que se refere à inserção das mulheres camponesas capixabas em espaços sociais e no trabalho, encontramos a permanência de uma dupla/tripla jornada de trabalho, no entanto, há possibilidade de rupturas, principalmente no seio da família, tanto no tratamento como no olhar para essa mulher e na consideração de suas tarefas diárias.

Ao encontro do refletido por meio dos discursos trazidos, corroboramos com Bakhtin (2003, p. 294) que "em cada época, em cada círculo social, em cada micromundo familiar, de amigos e conhecidos, de colegas, em que o homem cresce e vive, sempre existem enunciados investidos de autoridade que dão o tom, ... nas quais as pessoas se baseiam, as quais elas citam, imitam, seguem...".

Logo, tais discursos investidos de autoridade também perpassam as instituições campesinas, fazendo nelas refratar permanências ou possibilidades de rupturas quanto à condição da mulher nessa(s) comunidade(s), o que não poderia ser diferente no contexto das comunidades do campo no Espírito Santo.

\section{Os processos de escolarização das mulheres camponeses capixabas}

“... Nós não sabemos ler nada"; “... Terminei meus estudos com muita dificuldade"; “... Meu pai não nos deixou estudar. Eu queria muito estudar e ele não deixou"; "Depois de ter passado pela fase de maternidade, casamento, construção da própria família, ai comecei a ingressar na faculdade". Essas e outras narrativas nos impulsionam a interrogar: Como as mulheres camponesas capixabas se inseriram/inserem nos processos de escolarização? Qual o lugar ocupado pela educação escolarizada nas trajetórias das mulheres focalizadas neste estudo?

A partir dos indícios e pistas deixados pelas mulheres camponesas ao relatarem suas memórias a respeito de suas trajetórias de vida e, especificamente, sobre a inclusão/exclusão em processos de escolarização, buscamos compreender e 
problematizar

permanências

$\mathrm{e}$

descontinuidades em suas trajetórias, considerando, com apoio em Ginzburg (2007, p. 40), que “... nosso conhecimento do passado é inevitavelmente incerto, descontínuo, lacunar: baseado numa massa de fragmentos e de ruínas".

Tais fragmentos indiciam que os processos de inserção ou a exclusão das mulheres camponesas aqui visibilizadas estão intrinsecamente relacionados aos modos de organização das famílias, bem como ao lugar ocupado pelas referidas mulheres nos espaços domésticos e sociais. Segundo pesquisas sobre a agricultura familiar, “... as mulheres [camponesas] são confinadas ao espaço da casa, do roçado e da comunidade onde moram, defrontandose com ordens morais de gênero que impõem duras restrições ao ir e vir" (Cordeiro, 2007, p. 20). O relato de Dória revela a preocupação do pai em preparar as filhas para o trabalho e para a vida matrimonial:

... Meu pai não trabalhava só bebia, por causa disso, nós não sabemos ler nada. A escola era pertinho da nossa casa e a professora falava para ele nos deixar estudar. Ele respondia que não e indagava: 'Para quê estudar?' falava que precisávamos trabalhar, porque depois casava e não sabia trabalhar. Ele era muito ruim (Dória, 81 anos).

Encontramos similitudes entre $\mathrm{O}$ relato de Dória e o verso declamado nas casas de Portugal e do Brasil há cerca de cinco séculos: "mulher que sabe muito é mulher atrapalhada, para ser mãe de família, saiba pouco ou saiba nada" (Dias, 1984, apud Ribeiro, 2011, p. 79).

As mulheres camponesas são, por diversos meios, deixadas à margem da sociedade. É o que observamos na narrativa de Dória, que foi destinada à submissão. Submissa ao pai, enquanto filha e submissa ao marido, enquanto esposa. Vanilda narra situação similar: "Meu pai não nos deixou estudar. Eu queria muito estudar e ele não deixou" (85 anos).

Helena, ao contrário de Dória e de Vanilda, conseguiu estudar. Porém sua educação foi tardia, de modo que, os desafios por ela encontrados neste longo processo marcaram-na e são por ela rememorados e registrados.

... Terminei meus estudos com muita dificuldade, estudei à distância. Naquela época não se conseguia estudar, não tinha condição. Com a ajuda de um juiz casado com uma amiga minha que me ajudou, preparou os documentos para eu estudar. Aí eu consegui me formar no magistério. Sempre fui uma boa aluna, nunca tive nota vermelha, tenho facilidade em aprender (Helena, 92 anos).

Notamos que sua inserção no processo de escolarização tornou-se possível graças à mediação de um juiz, casado com sua amiga. Desse modo, há a 
mediação não apenas masculina, mas de uma pessoa que ocupava uma profissão privilegiada socialmente. Percebemos, nessa ótica, o predomínio do modelo patriarcal de sociedade, que fornece $o$ modelo no qual se calcava, na vida política e social, por conseguinte, as relações interpessoais. "Uma lei moral inflexível, superior a todos os cálculos e vontades dos homens, pode regular a boa harmonia do corpo social, e, portanto deve ser rigorosamente respeitada e cumprida" (Holanda, 1995, p. 85).

Até mesmo Karina encontrou dificuldades e obstáculos em sua formação escolar. Todavia, ao narrar o início de sua escolarização, a jovem destaca que as escolas atendiam as necessidades de sua realidade:

Sobre o processo de escolarização, minha primeira escolinha foi escola municipal unidocente 'do Pena', escolinha aqui pertinho de casa, onde estudei de $1^{\mathrm{a}}$ a $4^{\mathrm{a}}$ séries. Depois fui para a Escola Família Agrícola de São Bento do Chapéu, onde estudei de $5^{\mathrm{a}}$ a $8^{\mathrm{a}}$ séries. Isso nos anos de 2008 a 2011. De 2012 a 2015 eu cursei o Ensino Médio na Escola Família Agrícola de Olivânia. Fui para lá justamente para dar continuidade a este segmento de educação que estava tendo, que era escola família agrícola, voltada para nossa realidade, voltada para o campo, voltada para isso que vivia e vivo até hoje que é o trabalho na agricultura, na lavoura, na roça (Karina, 21 anos).
Diferentemente de Dória e Helena, Karina conseguiu ingressar em um curso superior. Em suas palavras: "Depois de ter passado pela fase de maternidade, casamento, construção da própria família, eu ingressei em 2016 na faculdade. Hoje estou no $4^{\circ}$ período do Curso de Licenciatura em Educação do Campo, na área de Ciências Humanas e Sociais" (Karina, 21 anos).

Mesmo considerando que a escolarização de Karina represente indícios de descontinuidades em relação aos processos excludentes, há permanências em sua trajetória: o casamento e a maternidade precoces.

De acordo com Bakhtin (2004, p. 42, grifo do autor) "a psicologia do corpo social não se situa em nenhum lugar interior... ela é, pelo contrário, inteiramente exteriorizada: na palavra, no gesto, no ato...”, sendo que, as “... formas de interação verbal acham-se muito estritamente vinculadas às condições de uma situação social dada e reagem... a todas as flutuações da atmosfera social (2004, p. 42).". Nesse caminho, os discursos aqui analisados representam uma realidade específica e suas implicações sócio-históricas desvelam situações sociais impostas à mulher e todos os seus efeitos que permanecem na atualidade, de modo mais ou menos perceptível. 
Ressaltamos a importância dos discursos aqui visibilizados, pois nos remete aos contextos sociais em que as mulheres capixabas estavam/estão inseridos. De fato, os discursos revelam o que se encontrava escondido ou negligenciado historicamente.

Dessa forma, a mulher camponesa capixaba encontrou/encontra significativos obstáculos em seus processos de escolarização, tendo em vista a tradição patriarcal e os desdobramentos desta, que marcam as relações familiares e sociais mais amplas. Contudo, as descontinuidades são presentificadas em suas narrativas. Como exemplo, encontramos a inserção das mulheres camponesas em cursos superiores, em especial, na Licenciatura em Educação do Campo (LEDOC), que busca reconhecê-las como protagonistas e, portanto, sujeitos históricos, ao considerar a realidade do campo como ponto de partida para os processos educativos.

\section{Algumas considerações}

$\mathrm{Na}$ perspectiva de que um texto (gênero discursivo) reflete e refreta a realidade concreta e, nesse sentido, os aspectos sociais, históricos, culturais e ideológicos que lhe são inerentes, compreendemos que as narrativas das mulheres camponesas capixabas evidenciadas neste estudo espelham uma condição em constante mudança, a despeito das permanências encontradas. Logo, a (in)conclusão da pesquisa torna-se potência na perspectiva de sua própria inconclusibilidade demandar novos movimentos dialógicos e a abertura das fronteiras para outros dizeres e possibilidades.

Com esse entendimento, a visibilidade de recorrências materializadas nas narrativas instiga-nos a refletir acerca de algumas questões específicas, dentre as quais a continuidade de uma jornada dupla e/ou tripla de trabalho da mulher camponesa capixaba, ainda para muitos naturalizada e desvalorizada, retratando, portanto, um modelo patriarcal de família/sociedade ainda marcadamente forte no campo. Logo, como assevera Paulilo (2009, p. 192), “... o trabalho fora de casa não torna as mulheres automaticamente mais independentes de seus maridos e atuantes politicamente", tampouco, não leva a uma preocupação semelhante com a desigualdade entre os gêneros. Portanto, a entrada dessa mulher em outras frentes de trabalho, dentre elas a docência, em grande parte não repercutiu em um olhar para as suas condições de vida e as atividades laborais que necessita desempenhar.

Em contrapartida, mesmo que esse olhar não seja abrangente, podemos 
distinguir que o desejo de efetiva participação na/da comunidade campesina deu visibilidade a essa mulher e a colocou em condição de importância nessa comunidade, haja vista que as posições de agricultora, dona de casa, mãe, mulher, professora, benzedeira... transparecem sua valoração e influência.

Entendemos que a partir desses deslocamentos, marcados pela atividade intensa da mulher camponesa capixaba em sua(s) comunidade(s), encontramos, hoje, a sua inserção ainda criança no processo de escolarização, bem como um protagonismo no âmbito doméstico e comunitário, haja vista diferentes entradas nesse espaços e, nesse sentido, a visibilidade e deferência por parte da sociedade local e mais ampla.

Ademais, traduzimos que a inserção da mulher camponesa capixaba no Ensino Superior e, mais especificamente, na Universidade Pública, possibilita o diálogo entre diferentes culturas e a visibilidade da atividade campesina como legítima e imprescindível, a qual enseja processos de rupturas não dantes pensados. Logo, a Licenciatura em Educação do Campo/UFES evidencia essa possibilidade no sentido desse olhar e desse deslocamento e da relevância que lhe é inerente.

\section{Referências}

Bakhtin, M. (2004). Marxismo e filosofia da linguagem: Problemas Fundamentais do Método Sociológico na Ciência da Linguagem. São Paulo: Editora HUCITEC. - (2003). Estética da criação verbal. 4. ed. São Paulo: Martins Fontes.

Bassanezi, C. (2004). Mulheres dos anos dourados. In Del Priori, M. (Org.). História das mulheres no Brasil (pp. 508-535). São Paulo: Contexto.

Caliari, R., Foerster, E., Merler, A., \& Paixão, Muri, L. M. B. (2013). Diálogos Interculturais em Terras Capixabas. Vitória (ES): EDUFES.

Cordeiro, R. (2007). Gênero em contextos rurais: A liberdade de ir e vir e o controle da sexualidade das mulheres no Sertão de Pernambuco. In Jacó-Vilela, A. M., \& Sato, L. (Orgs.). Diálogos em Psicologia Social (pp. 131-139). Porto Alegre: Editora Evangraf Ltda.

Del Priori, M. (Org.). História das mulheres no Brasil. São Paulo: Contexto.

D'Incao, M. A. (2004). Mulher e família burguesa. In Del Priore, M. (Org.). História das mulheres no Brasil (pp. 187201). São Paulo: Contexto.

Ginzburg, C. (2007). O fio e os rastros: verdadeiro, falso e fictício. São Paulo: Companhia das Letras.

(2002). Relações de força: história, retórica e prova. São Paulo: Companhia das Letras.

(1989). A Micro História e outros ensaios. Lisboa: DIFEL.

(1988). Os andarilhos do bem: feitiçarias e cultos agrários nos séculos XVI e XVII. São Paulo: Companhia das Letras. 
Holanda, S. B. (1995). Raízes do Brasil. 26. ed. São Paulo: Companhia das Letras.

Lopes, E. M. T., Faria Filho, L. M., \& Veiga, C. G. (Orgs.). (2000). 500 anos de educação no Brasil. Belo Horizonte: Autêntica.

Medeiros, L. S., \& Neves, D. P. (Orgs.). (2013). Mulheres camponesas: trabalho produtivo e engajamento político. Niterói: Editora Qualidade.

Moreau, F. E. (2003). Os índios nas cartas de Nóbrega e Anchieta. São Paulo: Anablume.

Neves, D. P., \& Motta-Maués, M. A. (2013). Apresentação: Parte 1: Mulheres camponesas e reprodução de grupos domésticos. In Medeiros, L. S., \& Neves, D. P. (Orgs.). Mulheres camponesas: trabalho produtivo e engajamento político (pp. 17-40). Niterói: Editora Qualidade.

Neves, D. P., Santos, P. T., \& Cruz, R. P. (2013). Introdução. In Medeiros, L. S., \& Neves, D. P. (Orgs.). Mulheres camponesas: trabalho produtivo e engajamento político (pp. 347-357). Niterói: Editora Qualidade.

Paulilo, M. I. (2009). Movimentos das mulheres agricultoras e os muitos sentidos da "igualdade de gênero". In Fernandes, B. M., Medeiros, L. S., \& Paulilo, M. I. (Orgs.). Lutas camponesas contemporâneas: condições, dilemas e conquistas, v.2: a diversidade das formas das lutas no campo (pp. 179-202.). São Paulo: Editora UNESP; Brasília, DF: Núcleo de Estudos Agrários e Desenvolvimento Rural.

Rangel, L. A. S. (2011). Feminismo ideal e sadio: os discursos feministas nas vozes das mulheres intelectuais capixabas. (Dissertação de Mestrado). Universidade Federal do Espírito Santo, Vitória.
Ribeiro, A. I. M. (2000). Mulheres educadas na colônia. In Lopes, E. M. T., Faria Filho, L. M., \& Veiga, C. V. (Orgs.). 500 anos de educação no Brasil (pp. 7994). Belo Horizonte: Autêntica.

Rocha, K. F. (2016). Mensageiras da liberdade: mulheres, abolicionismo $e$ recrutamento militar (Província do Espírito Santo 1836-1888). (Dissertação de Mestrado). Universidade Federal do Espírito Santo, Vitória.

Santos, B., Jesus, M. E. O., Oliveira, L. B., \& Oliveira, F. S. (2013). Um enfoque acerca da história e lutas do movimento de mulheres camponesas no município de Caetité-BA. In Anais do Simpósio baiano de geografia agrária e semana de geografia da UESB: o campo baiano na relação Estado, Capital, Trabalho: espaço de lutas. Universidade Estadual do Sudeste da Bahia, BA.

Silveira, L. (2015). Gênero, velhice $e$ geração: a violência familiar contra a mulher idosa em Vitória (ES), 2010-2012. (Dissertação de Mestrado). Universidade Federal do Espírito Santo, Vitória.

Simões, R. H. S., \& Franco, S. P. (2004). Arquivos, fontes e historiografia capixabas: tecendo espaços/tempos de reflexão, produção, socialização e investigação histórica da educação no Espírito Santo. In Anais do Congresso Brasileiro de História da Educação, 3., 2004, Curitiba. 1. Recuperado de: www.sbhe.org.br/novo/congressos/cbhe3/

Documentos/Individ/.../037.pdf

Siqueira, V. S. (2008). Mulher: entre o lar e o status de professora, uma questão de educação. (Dissertação de Mestrado). Universidade Federal do Espírito Santo, Vitória.

Suanno Neto, F. (2014). Poderes e família: domicílios multifacetados chefiados por mulheres: Aldêa Velha (ES). (Dissertação 
de Mestrado). Universidade Federal do Espírito Santo, Vitória.

Ao longo do texto, utilizamos os termos "campensina" e "camponesa" para nos referir à mulher do campo, assumindo ambos o mesmo sentido.

ii Este artigo apresenta reflexões parciais de pesquisa em andamento vinculada aos Projetos de Pesquisa Os processos formativos dos estudantes do curso de LEC/UFES: um olhar com e pelos Cadernos da Realidade e de extensão O Caderno da Realidade como instrumento de interlocução $e$ intervenção na comunidade dos estudantes de Licenciatura em Educação do Campo cujos desdobramentos efetivam-se, dentre outros, por meio de produção de artigos e Trabalho de Conclusão de Curso produzido por uma estudante da Licenciatura em Educação do Campo/UFES.

iii Para aprofundamento sobre a diversidade dos grupos indígenas que povoavam a região de Piratininga à época da colonização do Brasil, mencionada por Ribeiro (2011) ao tratar da compressão a respeito das mulheres indígenas, ver: Moreau, Felipe Eduardo (2003). Os índios nas cartas de Nóbrega e Anchieta. São Paulo: Anablume.

${ }^{\text {iv }}$ Esse levantamento foi realizado pelos autores e autoras considerando todos os títulos de dissertações e teses disponibilizados no Banco de Teses da CAPES, até o final do primeiro semestre de 2009, que tivessem como referência ou palavrachave não só o termo gênero (independentemente de ser tomado como conceito ou senso comum), mas também a distinção sexual homem e mulher, ênfase no estudo de condições de vida de mulheres e de homens, formas de produção de masculinidade, feminilidade e sexualidade (2013).

v Ao evidenciar cada enunciado/discurso, utilizaremos nomes-fantasias, no sentido da preservação identitária das mulheres co-produtoras de nossa pesquisa.

${ }^{\mathrm{vi}}$ As narrativas foram, primeiramente gravadas em áudio e, posteriormente transcritas para os Cadernos da Realidade, buscando a garantia de fidedignidade dos discursos.

vii A autora analisa revistas femininas que circularam no período: Jornal das Moças e $O$ Cruzeiro.

\author{
Informações do artigo / Article Information \\ Recebido em : 30/05/2018 \\ Aprovado em: 14/08/2018 \\ Publicado em: 23/12/2018 \\ Received on May 30th, 2018 \\ Accepted on August 14th, 2018 \\ Published on December 23th, 2018
}

Contribuições no artigo: $O$ primeiro autor participou da coleta, transcrição e análise dos dados; o segundo autor participou da análise dos dados, redação e revisão final do artigo; o terceiro e o quarto autor orientaram todas as etapas do trabalho, participaram da análise dos dados, redação do artigo e da revisão final do artigo. Todos aprovaram a versão final do artigo publicado.

Author Contributions: The first author participated in the collection, transcription and analysis of the data; the second author participated in the data analysis, writing and final revision of the article; the third and fourth author guided all the stages of the work, participated in the analysis of the data, writing of the article and the final revision of the article. All authors approval of the final version published.

Conflitos de interesse: Os autores declararam não haver nenhum conflito de interesse referente a este artigo.

Conflict of Interest: None reported.

\section{Orcid}

Deiviani de Oliveira

iD http://orcid.org/0000-0002-1732-1308

Luan Eudair Bridi

(iD) http://orcid.org/0000-0002-1008-5103

\section{Miriã Lúcia Luiz \\ (iD) \\ http://orcid.org/0000-0001-6825-1541}

Regina Godinho de Alcântara

http://orcid.org/0000-0002-5748-3918

\section{Como citar este artigo / How to cite this article}

APA

Oliveira, D., Bridi, L. E., Luiz, M. L., \& Alcântara, R. G. (2018). Trajetórias de mulheres camponesas no Espírito Santo: permanências e descontinuidades. Rev. Bras. Educ. Camp., 3(4), 1221-1248. DOI: http://dx.doi.org/10.20873/uft.2525-4863.2018v3n4p1221

ABNT

OLIVEIRA, D.; BRIDI, L. E.; LUIZ, M. L.; ALCÂNTARA, R. G. Trajetórias de mulheres camponesas no Espírito Santo: permanências e descontinuidades. Rev. Bras. Educ. Camp., Tocantinópolis, v. 3, n. 4, set./dez., p. 1221-1248, 2018. $\quad$ DOI: http://dx.doi.org/10.20873/uft.2525$\underline{4863.2018 v 3 n 4 p 1221}$ 